\title{
Intellectual disability among Bhutanese refugees referred to psychiatric service of BPKIHS
}

\author{
BK Deo ${ }^{1}$, L Mallick ${ }^{1}$, DR Shakya ${ }^{1}$, PM Shyangwa ${ }^{1}$, N Sapkota ${ }^{1}$, BR Adhikari ${ }^{1}$, RG Joshi ${ }^{1}$, AK Pandey ${ }^{1}$, \\ RR Singh ${ }^{2}$ \\ Department of Psychiatry ${ }^{1}$, Department of Pediatric and Adolescent Medicine ${ }^{2}$ \\ B.P. Koirala Institute of Health Sciences, Dharan, Nepal
}

\begin{abstract}
Background: Intellectual disability plays a significant role, especially in the field of rehabilitation. It becomes more important when people live in refugee camp for a long duration. Objective: To assess the level of intelligence and disability; and to sort out the illnesses comorbid with mental retardation in the Bhutanese refugees in eastern Nepal. Methods: Hospital based descriptive study was done using purposive sampling. Instruments used were: vineland social maturity scale, developmental screening test, seguin form board, standard progressive matrices and colored progressive matrices. Results: Samples were 42 with $64 \%$ females. Age range was 11-20 years. Among these referred cases, $45 \%$ had speech disorder and hearing loss and $31 \%$ had neurological disorders, including seizure disorders. Sixty-six percent had mild, $9 \%$ moderate and $19 \%$ severe mental retardation. Conclusion: Majority of the intellectually disabled Bhutanese refugees had mild mental retardation, followed by severe one. Seizure was a common co-morbidity in mental retardation.
\end{abstract}

Key words: Intelligence, intelligence quotient (I.Q.), mental retardation, seizure

\section{Introduction}

Intellectual disability, also known as mental retardation $(M R)$ is defined in the fourth edition of the diagnostic and statistical manual of mental disorders (DSM-IV of

\section{Address for correspondence}

Binod Kumar Deo

Assistant Professor

Department of Psychiatry

B.P. Koirala Institute of Health Sciences, Dharan

Email: binod_deo@yahoo.com
American Psychiatric Association, 1994) ${ }^{1}$ on the basis of 3 essential features: subnormal intellectual functioning, characterized by an intelligence quotient (IQ) lower than 70 and commensurate deficits in adaptive functioning (capacities for social and personal sufficiency and independence) and onset before 18 years. The measurement of intelligence is presumed to be based in most cases on the administration of an appropriate standardized 
assessment of intelligence. Deficits in adaptive skills are generally measured on instruments such as the recently re-revised vineland adaptive behavior scale. The approach to the definition of $M R$ is fundamentally the same in the tenth edition of the International Classification of Diseases (ICD-10) (World Health Organization, 1992). ${ }^{2}$ Various levels of $M R$ are specified in the DSM-IV: mild (IQ 50 to 69), moderate (IQ 35 to 49), severe (IQ 20 to 34) and profound (IQ $<20)$. Persons with IQ level 70 to 79 are termed as having borderline intelligence and those with IQ level 80 to 89 are termed as having dull average intelligence. Most persons with MR (approx. $85 \%$ of cases) in childhood have mild MR; followed by moderate (approx. 10\%), severe (approx. $4 \%)$ and profound MR (1-2\%) (Szymanski and King, 1999). ${ }^{3}$

Prevalence of mental retardation varies across countries and also within countries across different population. One of the oldest and most cited study, 'the Isle of Wight study' (Rutter and colleagues, 1976) ${ }^{4}$ noted that, about $2.5 \%$ of $9-11$ years old children would be classified as mentally retarded if IQ were the sole criterion but if the prevalence were based on those receiving services, this rate would be cut almost by half (1.3\%). Subnormal intellectual functioning is characterized by an intelligence quotient (IQ) lower than 70 , based in most cases on the administration of an appropriate standardized assessment of intelligence. Deficits in adaptive skills, which involve one's social and personal sufficiency and independence, are generally measured with instruments such as the recently re-revised vineland adaptive behaviour scale (Sparrow, 2005). ${ }^{5}$

Mental retardation is among the world's most complex and challenging problems. It is a multi dimensional phenomenon involving biopsycho-social factors. All developmental disorders tend to be 'stigmatizing disabilities'.

\section{Methods}

The study was undertaken in department of Psychiatry, B.P. Koirala Institute of Health Sciences, Dharan, Nepal, a tertiary care hospital of Eastern Nepal with subject enrollment during the period from July 2009 to June 2010. The study design was a hospital based descriptive one with a purposive and convenient sampling.

The hospital runs a psychiatry outpatient clinic. Bhutanese people living in refugee camps of Eastern Nepal with suspected subnormal intelligence were referred by primary health workers of the camps to the Psychiatry clinic of the hospital. All subjects were first assessed by a psychiatrist and then referred to psychologist for formal testing of Intelligence with Intelligence quotient (IQ). 
Different IQ assessment instruments were used depending on the age of the subjects as follows-

\section{Age group below 5 years}

1. Developmental screening test

2. Vineland social maturity scale

3. Seguin form board

\section{Below 5 to 12 years}

1. Colored progressive matrices

2. Developmental screening test

3. Vineland social maturity scale

4. Seguin form board (SFB)

\section{Above 12 years}

1. Standard progressive matrices

2. Others depending on the performances

Relevant information was recorded in a predesigned proforma. Co-morbid conditions were recorded as per the diagnoses of the departments referring or referred to as deemed necessary during the psychiatric assessment. A total of 42 subjects were assessed during the study period. All cases accompanied by at least one attendant and willing to cooperate with the study procedures were included in this study. Data was analyzed with appropriate descriptive statistics using SPSS 17.

\section{Results}

Out of total 42 subjects, 15 were male and 27 female. Majority of the subjects were young children, adolescents and youth below 20 years of age. Most of the subjects were unmarried $(85.7 \%)$, with $66.6 \%$ illiterate and $88.2 \%$ unemployed (Table 1 ).

Table 1: Gender, marital status, educational status, age and occupation distribution

\begin{tabular}{|l|l|l|l|}
\hline \multicolumn{2}{|l|}{ Categories } & Number of subjects & Percentage \\
\hline \multirow{3}{*}{ Gender } & Male & 15 & $35.8 \%$ \\
\cline { 2 - 4 } & Female & 27 & $64.2 \%$ \\
\hline \multirow{3}{*}{ Marital status } & Unmarried & 36 & $85.7 \%$ \\
\cline { 2 - 4 } & Married & 06 & $14.3 \%$ \\
\hline Educational status & Illiterate & 28 & $66.6 \%$ \\
\cline { 2 - 4 } & Literate & 14 & $34.3 \%$ \\
\hline \multirow{3}{*}{ Age } & $5-10$ years & 08 & $19.0 \%$ \\
\cline { 2 - 4 } & $11-15$ years & 13 & $31.0 \%$ \\
\cline { 2 - 4 } & $16-20$ years & 10 & $23.8 \%$ \\
\cline { 2 - 4 } & $21-25$ years & 02 & $04.7 \%$ \\
\hline
\end{tabular}




\begin{tabular}{|l|l|l|l|}
\hline \multirow{7}{*}{} & $26-30$ years & 04 & $09.4 \%$ \\
\cline { 2 - 4 } & $31-35$ years & 02 & $04.7 \%$ \\
\cline { 2 - 4 } & $36-40$ years & 01 & $02.3 \%$ \\
\cline { 2 - 4 } & Above 40 years & 02 & $04.7 \%$ \\
\hline Occupation & Unemployed & 37 & $88.2 \%$ \\
\cline { 2 - 4 } & Laborer & 03 & $07.1 \%$ \\
\cline { 2 - 4 } & Tailoring & 02 & $04.7 \%$ \\
\hline
\end{tabular}

Mild MR was the most common type/level among the intellectually disabled Bhutanese refugees of eastern Nepal visiting psychiatry service of BPKIHS (Table 2).

Table 2: Levels of mental retardation

\begin{tabular}{|l|l|l|l|}
\hline \multicolumn{1}{|c|}{$\begin{array}{c}\text { Level of } \\
\text { intelligence }\end{array}$} & $\begin{array}{c}\text { Range } \\
\text { of I.Q. }\end{array}$ & No. & \% \\
\hline $\begin{array}{l}\text { Dull average } \\
\text { intelligence }\end{array}$ & $80-89$ & 01 & 2.3 \\
\hline $\begin{array}{l}\text { Borderline } \\
\text { intelligence }\end{array}$ & $70-79$ & 01 & 2.3 \\
\hline Mild MR & $50-69$ & 28 & 66.6 \\
\hline Moderate MR & $35-49$ & 04 & 9.4 \\
\hline Severe MR & $20-34$ & 08 & 19.0 \\
\hline Profound MR & Below 20 & 00 & 0.0 \\
\hline
\end{tabular}

Majority of the subjects (81\%) had lack of competency, as revealed in the assessment (Table 3).

Table 3: Competency (average functioning) distribution

\begin{tabular}{|l|l|l|}
\hline $\begin{array}{l}\text { Competency } \\
\text { (Average functioning) }\end{array}$ & No. & $\%$ \\
\hline Household work & 4 & 9.4 \\
\hline
\end{tabular}

\begin{tabular}{|l|l|c|}
\hline Hygiene and self help & 3 & 7.1 \\
\hline Painting & 1 & 2.3 \\
\hline Lack of competency & 34 & 81.2 \\
\hline Total & 42 & 100.0 \\
\hline
\end{tabular}

Seizure disorder was the most common disease and speech difficulty the impairment (Table 4).

Table 4: Co-morbid disorders and impairments

\begin{tabular}{|l|l|l|l|}
\hline \multirow{4}{*}{$\begin{array}{l}\text { Co } \\
\text { morbidities }\end{array}$} & Disorders & No. & $\%$ \\
\cline { 2 - 4 } & Seizures & 04 & 9.4 \\
\cline { 2 - 4 } & Tuberculosis & 01 & 2.3 \\
\cline { 2 - 4 } & ADHD & 02 & 4.7 \\
\cline { 2 - 4 } GAD & 01 & 2.3 \\
\hline \multirow{2}{*}{$\begin{array}{l}\text { Other } \\
\text { deficits }\end{array}$} & Speech difficulty & 13 & 31.1 \\
\cline { 2 - 4 } & $\begin{array}{l}\text { Hearing } \\
\text { impairment }\end{array}$ & 07 & 16.6 \\
\cline { 2 - 4 } & $\begin{array}{l}\text { Neurological } \\
\text { deficit }\end{array}$ & 02 & 4.7 \\
\hline
\end{tabular}




\section{Discussion}

In our study, 42 patients assessed with the I.Q. test during the study period were included. They were refugees from Bhutan living in nearby shelter camps in eastern Nepal. Most of them had come to Pediatric OPD and were referred to Psychiatric OPD of BPKIHS for check up. After being examined by the psychiatrists, those with learning disabilities and delayed milestones, i.e. subnormal intelligence were referred to psychology section for intelligence assessment. Mental retardation is reported as common diagnosis among child and adolescent out-patients of this department. ${ }^{6}$ An intensive study about its severity and associated disability among Bhutanese refugees referred for psychiatry service is expected to throw light on some important issues.

We had more (1.8 times) female subjects with intellectual disability in this study. Literacy rate was $34.3 \%$. In our study, $50 \%$ of the cases were below 16 years which resembles the study of Shrestha SM (1999) ${ }^{7}$ in Nepal where $40 \%$ of the mentally retarded were below 14 years of age. Seizure disorder was found to be $9.4 \%$ in the present study, which is similar to findings of Izuora $(1985)^{8}$ where $12.5 \%$ epilepsy cases were found. Corbet et al (1975) ${ }^{9}$ surveyed all severely mentally retarded children (whether in hospital or outside) originating from a London suburb. One third of these children had experienced seizures at some time or the other, and one fifth had at least one episode of seizure in the year before the enquiry. And, a report from this department shows that mental retardation was found in $4 \%$ of seizure cases visiting its clinic service. ${ }^{10}$ Gelder M $(1993)^{11}$ reported autism and over activity syndromes to be common among the mentally retarded children and our study has $4.7 \%$ with ADHD.

In our finding, majority (66\%) had mild MR keeping with most reports. ${ }^{1,2,11}$ And, $28.4 \%$ were moderate to severe mentally retarded which was close to findings of Ramma $S$ $(2004)^{12}$ with $20 \%$ with grade $V$ on Raven's progressive Matrices, i.e. equivalent to moderate-severe mental retardation. A study in department of Pediatrics and adolescent medicine, BPKIHS categorizing the MR subjects into only 2 categories, i.e. mild and severe reported the ratio of mild to severe of 1:2. This also indicates the preponderance of mild type of MR though there is a slight variation in proportions of the types of MR. Since all suspected MR in refugee camps were referred in our study, the proportion of mild cases were relatively more than in the study of Gauchan et al. ${ }^{13}$

We had limitations in this study with: 1. small sample size, 2. biased sample in a way since the subjects were referred intensively for intelligence assessment, 3 . inability to explore 
in depth into the etiological factors and 4. Heterogeneous sample in terms of referral sources in the institute (main being Pediatric OPD).

\section{Conclusion}

Mild mental retardation was the most common type among Bhutanese refugees seeking help from BPKIHS. Seizure disorder was the main co-morbid illness among MR patients; along with hearing disability, speech defects and other neurological deficits. A multi-disciplinary approach and community based study are needed for further evaluation and intervention to reduce the distress and disability of these refugees.

\section{Reference}

1. American Psychiatric Association. Diagnostic and Statistical Manual of Mental disorders, $4^{\text {th }}$ ed. Washington, D.C; 1994.

2. World Health Organization. International Classification of Diseases. W.H.O. Geneva; 1992.

3. Szymanski LS, King BH, Goldberg B et al. Diagnosis of Mental disorders in people with Mental retardation. In: Reiss S, Aman MG (eds). Psychotropic medications and Developmental Disabilities: The International Consensus Handbook. Columbus, Ohio State University Press, 1999:3-17.
4. Rutter M, Graham P, Chadwic O, Yule W. Adolescent turmoil: fact or fiction. Journal of Child psychology and Psychiatry. 1976; 17:35-36.

5. Sparrow S, Balla D, Cicchetti D. Vineland Adaptive Behaviour Scales. Circle Pines, American Guidance Service; 2005.

6. Shakya DR. Psychiatric morbidity profiles of Child and adolescent Psychiatry out-patients in a tertiary-care hospital. J Nepal paediatr soc. 2010; 30(2):79-84.

7. Shrestha SM. Country Report: Nepal. In: Maskey BK and Adhikari RK (eds). Equalization of opportunities for the mentally retarded. 1999, Association for the welfare of mentally retarded, Kathmandu. p. 409.

8. Izuora Gl. Aetiology of Mental retardation in Nigeria. Central Afr. J. Med.1985; 31(1):13-16.

9. Corbett JA, Harris R, Robinson RG. Epilepsy. In: Wartis J (ed.). Mental retardation and developmental disabilities: an annual review. 1975. Vol. VII; Brunner-Mazel, New York.

10. Shakya DR. Psychiatric symptoms and disorders in seizure cases referred to psychiatric out-patient service. J Neuroscience and Behavioural Health. March 2013; 5(1):13-19. 
11. King $\mathrm{BH}$, Hodapp RM, Dykens EM. Mental Retardation. In: Sadock BJ, Sadock VA (eds.). Comprehensive Textbook of Psychiatry, 8th Edition, Lippincott Williams \& Wilkins, 2005; 3079-3106.
12. Ramaa S. Two decades of research on learning disabilities in India. Dyslexia. 2000; 6:268-83.

13. Gauchan E, Singh RR, Bhatta NK, Saxena AK, Deo BK. Study of Mental retardation in Children at BPKIHS. Unpublished- MD thesis. 2005; 56-57. 